\title{
Perfil dos Egressos de Computação do Interior da Amazônia no Mercado de Trabalho
}

\author{
Luiz H. C. Nunes ${ }^{1}$, Josivan R. Reis ${ }^{2}$, Carla M. Paxiúba ${ }^{1}$, Márcio J. M. Ponte ${ }^{1}$, \\ Mariana W. B. Nascimento ${ }^{3}$, Roberto P. Nascimento ${ }^{1}$ \\ ${ }^{1}$ Instituto de Engenharia e Geociências - Universidade Federal do Oeste do Pará \\ (UFOPA) Santarém - PA - Brasil \\ ${ }^{2}$ Universidade Federal do Oeste do Pará (UFOPA) - Oriximiná - PA - Brasil \\ ${ }^{3}$ Instituto Federal do Pará (IFPA) - Óbidos - PA - Brasil \\ \{carla.paxiuba, marcio.ponte, roberto.nascimento\}@ufopa.edu.br \\ \{luiz.nunes159, mariwb14\}@gmail.com, josivan.reis@ufopa.edu.br
}

\begin{abstract}
To know the profile of computing graduates in Brazil is a necessity and also a challenge. Thus, this paper raises data about the computer graduates of some Higher Education Institutions from the west of Pará (UFPA and UFOPA) and show the profile of these graduates from the first technology course in the region, Data Processing Technologist (TPD) to the current courses. The study was carried out using the Quantitative Research method, using a questionnaire. The article also presents an analysis a return of income by gender.
\end{abstract}

Resumo. Conhecer o perfil dos egressos de computação no Brasil é uma necessidade e também um desafio. Dessa forma, este trabalho visa levantar dados sobre os egressos de computação das Instituições de Ensino Superior (IES) públicas do Oeste do Pará (Universidade Federal do Pará - UFPA e Universidade Federal do Oeste do Pará - UFOPA) e apresentar o perfil desses egressos desde o primeiro curso de tecnologia da região, Tecnólogo em Processamento de Dados (TPD), até os cursos vigentes. O estudo foi realizado através do método de Survey de pesquisa quantitativa, utilizando questionário. O artigo apresenta ainda um recorte dos ingressos por gênero.

\section{Introdução}

Nos últimos tempos, um dos principais objetivos da Universidade era formar profissionais qualificados e aptos para ingressar no mercado de trabalho. No entanto, com o contemporâneo e complexo cenário social, econômico, político juntamente com a revolução da educação na era digital, as universidades se veem com a necessidade de ir além, buscando formar líderes que sejam capazes de enfrentar e solucionar os desafios da indústria 4.0. Portanto, obter um feedback dos profissionais que já concluíram o curso de graduação é uma fonte de conhecimento de extrema relevância, que contribui para que as instituições de ensino realizem a avaliação e evolução das metodologias de ensino dos cursos de graduação e pós graduação.

É notória a preocupação em obter informações de como os egressos do ensino superior estão se estabelecendo no mercado de trabalho, principalmente no que se refere ao 
profissional de Tecnologia da Informação e à questão de gênero. Desse modo, este artigo apresenta uma pesquisa realizada com egressos dos cursos de computação da Universidade Federal do Oeste do Pará. O objetivo das análises é delinear o perfil dos egressos juntamente com a localização e a posição desses egressos no mercado de trabalho, assim como apresentar os ingressos por gênero desde o primeiro curso de computação na região.

\section{Metodologia}

A pesquisa iniciou-se no ano de 2019, utilizando o método de pesquisa survey, por meio da aplicação de questionário online ${ }^{1}$ com os egressos dos cursos de TPD, BSI e BCC da UFPA e UFOPA, totalizando 275 formados. O formulário foi encaminhado via e-mail para todos os egressos que se obteve contato, atingindo 55 respostas positivas, equivalendo $20 \%$ dos egressos.

A Tabela 1 expressa a relação de egressos por gênero em relação à taxa de participação na pesquisa até o presente momento.

Tabela 1. Egressos que responderam à pesquisa

\begin{tabular}{|c|c|c|}
\hline Egressos participantes da pesquisa & Egressos & Porcentagem \\
\hline Masculino & 37 & $67,27 \%$ \\
\hline Feminino & 18 & $32,73 \%$ \\
\hline
\end{tabular}

O formulário de pesquisa abrange 22 perguntas objetivas com o propósito de compreender o perfil desses egressos inseridos no mercado de trabalho, sobre assuntos referentes à situação atual do egresso como: ocupação, local de trabalho, remuneração e informações da formação acadêmica. Os elementos apurados a partir da aplicação do questionário são representados por meio de gráficos e tabelas com as análises quantitativas pertinentes ao estudo.

\section{Análises}

\subsection{Ocupação}

Em relação aos dados referentes à ocupação dos egressos, a Figura 1 apresenta as ocupações atuais dos 55 egressos que responderam a pesquisa até o momento. A resposta com maior frequência foi a de Docente $(16,36 \%)$, as outras ocupações estão distribuídas entre Administrador Telecom (1,82\%), Agente Administrativo (1,82\%), Analista de $\mathrm{TI}^{2}(3,64 \%)$, Analista de Redes (1,82\%), Analista de Dados e Técnico de Informática (1,82\%), Assistente Administrativo (3,64\%), Assistente de Atendimento (1,82\%), Auxiliar Administrativo (3,64\%), Bolsista (3,64\%), Chefe de Divisão de Redes e Serviços de Internet (1,82\%), Desenvolvedor de Software (3,64\%), Empreendedor (1,82\%), Estudante $(1,82 \%)$, Gerência de TIC's ${ }^{3}(1,82 \%)$, Gerência de Vendas $(1,82 \%)$, Gestor de TI (1,82\%), Pós-doutorando (1,82\%), Secretário Executivo (1,82\%), Servidor Público $(10,91 \%)$, Suporte em Sistemas $(1,82 \%)$, Técnico em Mineração $(1,82 \%)$ e Técnico de TI $(7,27 \%)$. Há também os que responderam não ter vínculo empregatício $(20,00 \%)$.

\footnotetext{
${ }^{1}$ baseado no trabalho [Figueiredo et al. 2018]

${ }^{2}$ Tecnologia da Informação

${ }^{3}$ Tecnologia da Informação e Comunicação
} 


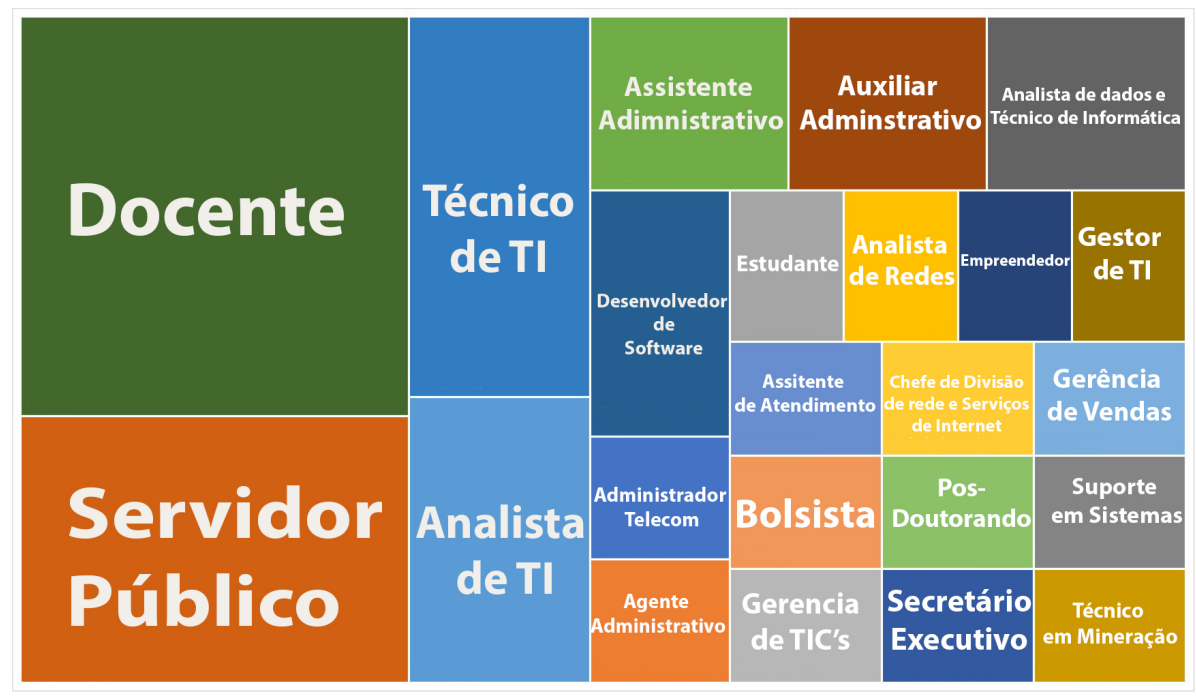

Figura 1. Ocupação dos egressos de computação

\subsection{Formação}

A pesquisa ainda revelou que $85,45 \%$ dos egressos que participaram da pesquisa fizeram uma segunda graduação e/ou pós-graduação. A Tabela 2 exibe os títulos complementares dos egressos, que são classificados em: Graduação, Especialização Lato Sensu, Mestrado e Doutorado, e suas respectivas quantidades e porcentagens.

\section{Tabela 2. Títulos Complementares dos Egressos}

\begin{tabular}{|l|c|c|}
\hline Titulação & Egressos & $(\%)$ \\
\hline Graduação (Segunda) & 6 & 10,91 \\
\hline Especialização & 21 & 38,18 \\
\hline Mestrado & 16 & 29,09 \\
\hline Doutorado & 4 & 7,27 \\
\hline
\end{tabular}

Pode-se analisar que esses dados demonstram a busca dos egressos por melhor formação e qualificação profissional, para que o posicionamento no mercado de trabalho seja mais satisfatório.

\subsection{Ingressos por gênero}

Para esta investigação foram analisados dados relativos ao número de ingressantes por ano e sexo nos cursos de TPD, BSI e BCC. A análise foi realizada a partir do ano de criação de cada curso. Os dados foram extraídos do Sistema Integrado de Gestão de Atividades Acadêmicas - SIGAA da UFOPA e da Diretoria do CIAC (Centro de Registro e Indicadores Acadêmicos) da UFPA.

Nas Figuras 2 e 3 têm-se o número de ingressantes por ano e sexo nos cursos de TPD, BSI e BCC. Uma questão importante a ser analisada, é a diferença de número entre homens e mulheres que aumentou com o passar do tempo nos cursos de computação.

A Figura 2 apresenta os ingressos do curso de TPD de 1994 até 2003. No primeiro ano do curso ingressaram 52 discentes ( 30 homens e 22 mulheres), a turma era composta 
de $42,30 \%$ de mulheres. A entrada de mulheres se manteve ligeiramente proporcional a de homens, com uma brusca mudança no último ano do curso com a menor entrada de mulheres desde o início do curso.

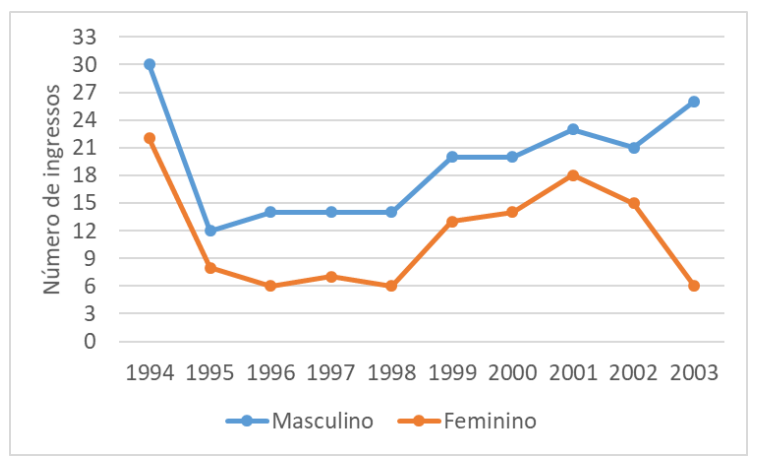

Figura 2. Ingressos de TPD por recorte de gênero

A Figura 3(a) apresenta os ingressos do curso de BSI de 2004 a 2010 e de 2015 a 2019. Embora o curso tenha iniciado em 2004, os alunos de TPD de 2001 a 2003 tinham a opção de migrar para o curso de BSI e, no gráfico, esse período (2001 - 2003) retrata o número de alunos que migraram para o curso de BSI. De 2003 a 2010 houve um aumento no número de mulheres, em 2010 houve a maior oferta de vagas no curso de BSI, totalizando 50 ingressos, 15 (30\%) mulheres e 35 (70\%) homens. O curso de BSI só voltou a ser ofertado em 2015 e, desde então, o número de mulheres vem diminuindo e em 2019 a entrada de mulheres foi de apenas (2) 7,14\% em relação aos homens (26). O BCC é o curso que tem atraído menos mulheres e, consequentemente, apresenta a maior diferença do número de entrada de mulheres em relação aos homens, como mostra a Figura 3(b), sendo a maior porcentagem em 2012 e 2015 com respectivamente, 20,59\% e 19,44\%, ambos com 7 mulheres. O ano com menos entrada foi em 2014 com apenas $8,33 \%$ ( 2 mulheres e 22 homens).

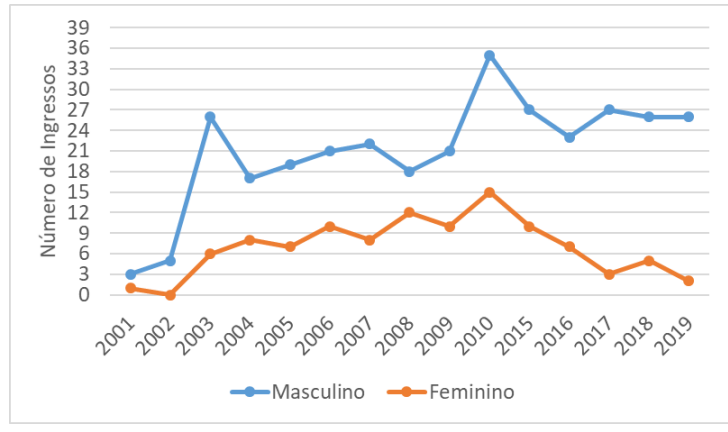

(a) Ingressos de BSI

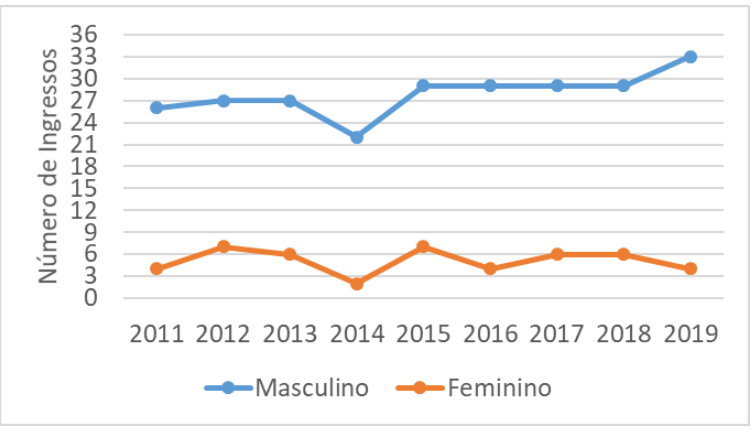

(b) Ingressos de $\mathrm{BCC}$

Figura 3. Ingressos por recorte de gênero

Os dados analisados vão ao encontro com o que foi apresentado em [Castro 2013], onde a autora aponta que ainda é baixo o número de mulheres que ingressam em cursos de tecnologia.

Segundo [Drehmer 2017], embora o número de cursos de computação tenha crescido 586\% no Brasil nos últimos 24 anos, o índice de mulheres matriculadas neles caiu 
$15,53 \%$. Esta pesquisa não entrou no aspecto de investigar os motivos que estão levando a redução do número de mulheres ingressantes na computação, mas em seu trabalho, a autora destaca o arranjo cultural como um importante fator a ser considerado.

\section{Considerações Finais}

O artigo apresenta um recorte da análise do perfil dos egressos do curso de Tecnologia em Processamento de Dados (TPD), Bacharelado em Sistemas de Informação (BSI) e Bacharelado em Ciência da Computação (BCC) das Instituições de Ensino Superior (IES) do Oeste do Pará. A partir dos dados levantados foi possível discutir sobre a posição dos egressos no mercado de trabalho, formação e análise dos ingressos por recorte de gênero.

As análises apontam a diferença do número de ingressantes entre gêneros. Esses dados são relevantes para os argumentos de novas políticas para incentivar as mulheres no curso de computação, sendo imprescindível que as instituições de ensino estude os egressos e uma possível reformulação do curso e manutenção acadêmica.

Como trabalhos futuros, pretende-se investigar taxa de evasão dos três cursos (TPD, BSI e BCC), a renda e a localização dos seus egressos para melhor adaptação ao contexto da educação na era digital.

\section{Referências}

Castro, B. G. (2013). Afogados em contratos: o impacto da flexibilização do trabalho nas trajetórias dos profissionais de TI. Tese (doutorado no instituto de filosofia e ciências humanas), Universidade Estadual de Campinas (UNICAMP).

Drehmer, R. (2017). Por que as mulheres ainda são minoria na área de TI? Disponível em: https://mdemulher.abril.com.br/trabalho/ por-que-as-mulheres-ainda-sao-minoria-na-area-de-ti/.

Acessado em Março de 2020.

Figueiredo, K. S., Azevedo, J. K. N., Azevedo, J. G., Santos, K. A. A., Gomes, R. S. R., Ventura, T. M., and Maciel, C. (2018). Perfil dos Egressos e Egressas de Computação de Mato Grosso no Mercado de Trabalho. In IX Computer on the Beach, volume 9, pages 297-306. 